\title{
BILATERAL BAND-SHAPED DEEP KERATITIS AND IRIDOCYCLITIS IN SYSTEMIC LUPUS ERYTHEMATOSUS*
}

\author{
BY \\ O. HALMAY AND K. LUDWIG \\ Department of Medicine and Ophthalmology, Szombathely County Hospital, Hungary
}

IN recent years more and more cases of systemic lupus erythematosus (S.L.E.) have been noted all over the world. The frequency of this disease is such that 400 patients have been treated in the Los Angeles County General Hospital (3,500 beds) in the last 10 years. Reports in the literature show that the incidence is higher than had been thought earlier, and its relatively benign and chronic nature has been revealed by better diagnostic methods.

A survey of the literature has indicated that ocular changes are relatively infrequent and are restricted chiefly to the retina, no cases of keratitis and iridocyclitis being noted. Insufficient documentation has made it difficult to recognize the criteria by which diagnosis was established.

In the last 4 years we have treated 24 cases of systemic lupus erythematosus at the Szombathely County Hospital. The diagnosis was established by the characteristic clinical picture and a positive L.E.-cell test or by verified histological examination (Ludwig, 1960-62). In the following proved case we found bilateral band-shaped keratitis and iridocyclitis; the lesions improved strikingly after treatment with steroids and antimalarials.

\section{Case Report}

A 37-year-old woman was admitted to hospital on February 11, 1963, with a rash and joint pains. One month before admission an erythematous skin rash had appeared on the extremities and later on the face and trunk. The eyelids became swollen and the eyes red and photophobic. The patient also had frequent headaches, dryness of the mouth, and pains in the joints of the shoulders and knees.

Examination.- Her general condition appeared to be good. The temperature was $37 \cdot 6^{\circ} \mathrm{C}$, and the weight $48 \mathrm{~kg}$. There was typical butterfly erythema of the face and neck (Fig. 1, opposite). Reddish exanthemata were present on both legs (Fig. 2, opposite). The pulse rate was 116 per minute and the blood pressure $120 / 60 \mathrm{~mm}$. $\mathrm{Hg}$. Other findings were normal.

Bilateral ciliary injection and conjunctival hyperaemia were present. In the centre of the cornea corresponding to the palpebral fissure there was a typical greyish-white band-shaped infiltration which consisted mostly of hyaline granules. The infiltration was located near Descemet's membrane, reaching into the posterior part of the substantia propria. The upper and lower parts of the cornea were clear (Fig. 3). The average width of the band was $3.5 \mathrm{~mm}$. Slit-lamp examination revealed an entirely clear area of the cornea $1.5 \mathrm{~mm}$. in width at each end of the band. Fresh greyish-white keratic precipitates could be detected on the posterior surface of the lower and middle parts of the cornea, in a triangular area with the peak upwards. There was diffuse Tyndallization in the aqueous fluid. The pupils were slightly smaller than normal and reacted sluggishly. The visual acuity of the right eye was $5 / 10$, and that of the left $5 / 8$. The fundi were normal. 


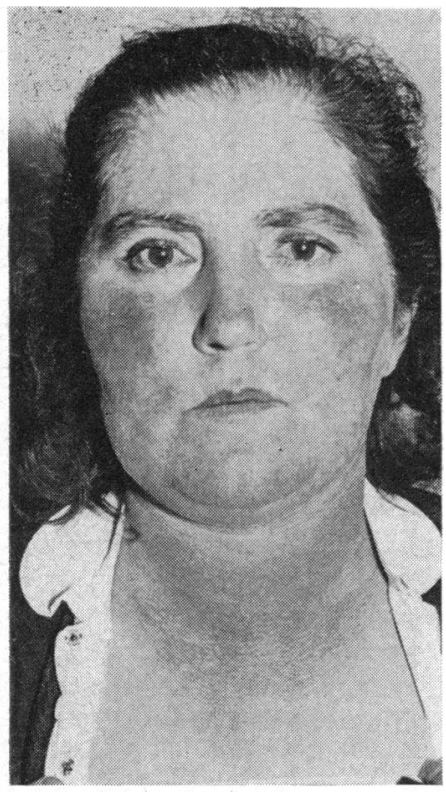

Fig. 1.-Erythema of face and neck.
FIG. 3.-Band-shaped infiltration in centre of cornea near Descemet's membrane.

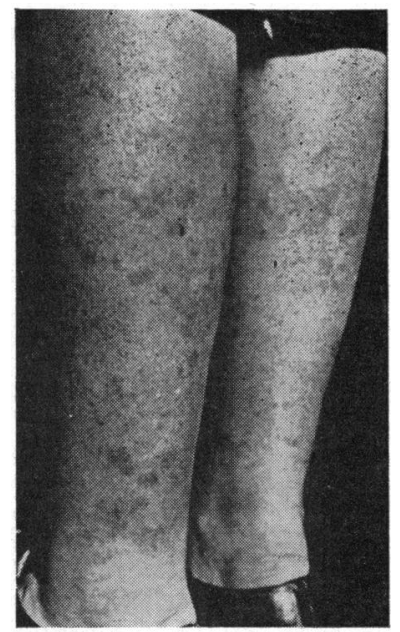

Fig. 2.-Exanthemata on both legs.

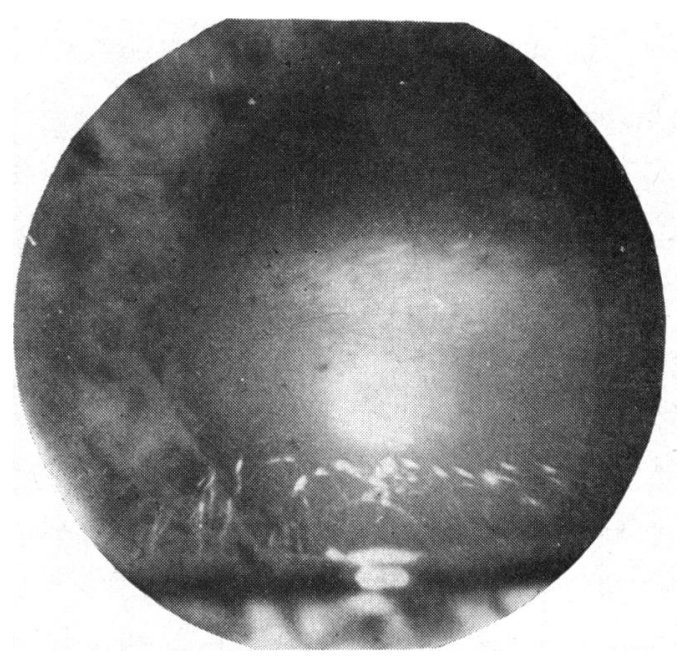

Laboratory Findings-The L.E.-cell test, performed by the method of Dacie (1956) modified by one of us (Ludwig, 1963), showed typical L.E.-cells (more than five). Red blood cells $2 \cdot 8$, haemoglobin $9 \mathrm{~g}$. per cent., white blood cells 5,000. The blood smear showed polymorphonuclear neutrophils 90 per cent., and lymphocytes 10 per cent. Erythrocyte sedimentation rate (E.S.R.) $53 \mathrm{~mm}$./hr. Platelets 160,000 . Serum iron 53 gamma per cent. Nonprotein nitrogen $30 \mathrm{mg}$. per cent. Creatinine clearance $59 \mathrm{ml}$.

Serum electrophoresis showed albumin 47 per cent., $\alpha-1$ globulin 4.8 per cent., $\alpha-2$ globulin 9.6 per cent., $\beta$-globulin 11.0 per cent., $\gamma$ globulin 27.6 per cent.

Thymol turbidity $2.5 \mathrm{U}$. Serum bilirubin $0.4 \mathrm{mg}$. per cent. Gold-sol ++ .

Wassermann reaction negative. Urine analysis negative. Addis-Sternheimer count normal. Renal concentrating capacity normal.

Throat culture showed Staphylococcus albus and aureus.

Chest and abdominal $x$ rays negative. 
Clinical Course.-The typical erythematous rash and positive L.E.-cell tests indicated the diagnosis of S.L.E. The patient was given $30 \mathrm{mg}$. prednisolone per day, raised later to $40 \mathrm{mg}$., accompanied by antibiotics. She was given two blood transfusions under the cover of the steroids without any reaction. Atropine was instilled into the eyes twice daily and Adreson five times a day.

After one week the general condition had improved. The E.S.R. fell to $37 \mathrm{~mm}$./hr. The skin rash repeatedly recurred after transient improvement, reappearing on new areas of the skin. The right eye improved but many keratic precipitates were still noted on the posterior surface of the cornea. The precipitates in the left eye were mostly absorbed though the eye remained inflamed. The infiltration of both corneae was unchanged.

The general condition was good 2 weeks later (March 2) but some fever was present. The skin rash flared up, and both eyes became inflamed. The keratic precipitates had disappeared entirely from the left eye but some persisted in the right eye. A few cells were observed in the aqueous humour of each eye. The intensity of the corneal infiltration was only slightly decreased. The visual acuity in the right eye was 5/8, and in the left 5/6. The daily dose of Prednisolone was raised to $60 \mathrm{mg}$. on account of the general activity of the disease process.

3 days later (March 5) the patient became afebrile and the skin rash less intense. Further erythematous lesions appeared, however, accompanied by some ciliary injection.

During her stay in hospital we were able to observe the flare-up of the skin lesion on four occasions, always in association with an increased congestion of the ciliary vessels. Prednisolone $60 \mathrm{mg}$. daily proving insufficient to control the activity of the disease, Nivaquine was given in daily doses increasing from 150 to $900 \mathrm{mg}$. while the same dosage of Prednisolone was continued. The patient thus received $900 \mathrm{mg}$. Nivaquine per day for 10 days and then $600 \mathrm{mg}$. daily until her discharge from hospital.

On this treatment she improved rapidly. By March 22 she was afebrile, the E.S.R. decreased to $4 \mathrm{~mm}$./hr, the skin rash faded gradually, and the exacerbations subsided. Cells and keratic precipitates in the anterior chamber were entirely absorbed, and the infiltration of the left cleared, but that in the right eye decreased only slightly.

The patient was discharged from hospital on April 6. Her general condition was excellent, and she had no complaints. Temperature normal, weight $51 \mathrm{~kg}$. E.S.R. $10 \mathrm{~mm} . / \mathrm{hr}$, R.B.C. 3.7, $\mathrm{Hb} 11.8$ g. per cent., W.B.C. 4,600. Urine analysis normal. Creatinine clearance normal. Since March 22 no fresh erythema had occurred and the rash had faded leaving some skin pigmentation. There were no ocular symptoms and the corneal infiltration had decreased in intensity. The visual acuity was $5 / 5$ in each eye.

Follow-up Examination (May 5).-The patient had no complaints, although moderate moon-face had developed. The erythema on face and neck was barely discernible, but there was slight pigmentation on the arms and legs and both hands and both feet were erythematous. R.B.C. $4 \cdot 4$, Hb 13.9 g. per cent., W.B.C. 4,200. A blood smear showed polymorphonuclear neutrophils 70 per cent., monocytes 11 per cent., and lymphocytes 10 per cent. E.S.R. $20 \mathrm{~mm}$./hr $\alpha-2$ globulin $7 \cdot 3$ per cent. $\gamma$-globulin 17.6 per cent. L.E.-cell test negative.

The condition of the eyes was the same as on discharge.

$25 \mathrm{mg}$. Prednisolone and $600 \mathrm{mg}$. Nivaquine daily were continued as maintenance therapy.

\section{Discussion}

The infrequent ocular manifestations of systemic lupus erythematosus chiefly affect the retina. Tumulty (1954) found cytoid bodies in 25 per cent. of this 105 patients. Soffer and Bader (1952) found 38 per cent. of retinal lesions, but Vachtenheim and Smid (1962) found only 14.2 per cent. and Petranyi (1958) only 9 per cent.

The retinal changes (cytoid bodies, intraretinal haemorrhage, septic choroiditis, and papilloedema) reported were observed primarily in the pre-terminal stage of the disease. Hill (1957) suggested that even the retinal lesions were rare except in acute and terminal cases; he did not regard cytoid bodies as specific because they also occur in hypertensive and diabetic retinopathy. 
Nevertheless, in the early phase of systemic lupus erythematosus, we noted symmetrical ocular lesions which may be regarded as early ophthalmic manifestations of the underlying disease.

Ocular lesions affecting the eyelids, conjunctiva, retina, uvea, and optic nerve were described in systemic lupus erythematosus by Maumenee (1956) but the cornea was not mentioned. Ten Doesschate (1956) reported a case of discoid erythematosus with superficial keratitis.

Band-shaped keratitis and iridocyclitis are common in cases of collagen disease, but have not previously been reported specifically in systemic lupus erythematosus. In our case the following points appear to be noteworthy:

(1) The ocular symptoms occurred simultaneously with the skin manifestations and other pathological changes. All these symptoms were carefully observed by us for some weeks.

(2) The general activity of the systemic lupus erythematosus parallelled the ocular symptoms. Contardo (1956) observed a correlation between the gravity of rheumatoid arthritis and the intensity of ocular changes.

(3) On combined Prednisolone-Nivaquine therapy the patient's condition returned to normal, with improvement of the keratitis and healing of the iridocyclitis.

(4) The connexion of band-shaped keratitis and iridocyclitis with systemic lupus erythematosus is supported by the following observations:

(i) Keratitis, especially the band-shaped form, often associated with iridocyclitis, is a striking feature of the "wider" group of collagen diseases.

(ii) Histologically articular tissue resembles the tissue of the uveal tract, and the uvea is closely related to the posterior segment of the cornea (Thomas, 1955).

(iii) The corneal infiltration which appears in some cases remains unexplained, but certain physico-chemical factors may play a role besides the above-mentioned endogenous tissue factors. The band-shaped keratitis occurs on the corneal surface which was exposed to exogenous trauma, such as cold, heat, desiccation, and light.

(iv) In our case light could be regarded as the main exogenous factor, associated with well-known sensitivity of systemic lupus erythematosus patients to sunlight.

The cornea is mentioned among the injured ocular structures in collagen disease by Maumenee (1956) in periarteritis nodosa and rheumatoid arthritis. Rheumatoid arthritis and systemic lupus erythematosus are closely related, and Bencze and Lakatos (1963) have suggested that systemic lupus erythematosus, chronic discoid lupus, rheumatoid arthritis, and Sjögren's syndrome should be grouped under the name of "polysystemic rheumatoid disease". It is suggested that the same mechanism may be responsible for the development of band-shaped keratitis and iridocyclitis in S.L.E. as in Still's disease. Band-shaped keratitis has been reported in 9 per cent. of cases of Still's disease by Sury (1952).

The corneal lesions described by Contardo (1956), who studied the ocular changes in 200 patients with collagen disease, included recurrent corneal ulcers, keratoconjunctivitis sicca or Sjögren's syndrome, and superficial or deep keratitis. It appeared, furthermore, that keratitis may appear in three forms-band-shaped, keratitis sicca, and disciform keratitis. S.L.E. was not directly mentioned by this author who was dealing with collagen diseases in general. He is the only author 
known to us who has mentioned band-shaped keratitis in the narrower group of collagen diseases.

Our opinion is that the ocular changes noted by us appear frequently in S.L.E. and can be regarded as the early ophthalmic manifestations of this condition. Earlier and more frequent diagnosis demands closer collaboration between physician and ophthalmologist. It is suggested that the early and repeated use of the slit-lamp microscope in every case of S.L.E. and also of other collagen diseases is important, because the minute ocular lesions cannot be seen by the naked eye. Our experience has shown that combined steroids and antimalarials heal both the underlying disease and the ophthalmic lesions.

\section{Summary}

The frequency of ocular manifestations in systemic lupus erythematosus is discussed. No reference could be found in the literature to band-shaped keratitis and iridocyclitis in a case of verified systemic lupus erythematosus.

A case of systemic lupus erythematosus with band-shaped keratitis and iridocyclitis is reported, with a detailed description of the changes in the ocular lesions on continued Prednisolone-Nivaquine therapy.

Previous data on the relationship of keratitis and the collagen diseases are reviewed and evidence is discussed concerning the relationship of deep keratitis to systemic lupus erythematosus. Ocular manifestations may occur not only in the pre-terminal but also in the early stages of systemic lupus erythematosus. Repeated examinations with the slit-lamp microscope are advised. Combined treatment with steroids and antimalarials is recommended.

\section{REFERENCES}

Bencze, G., and Lakatos, L. (1963). Rheum. Balnes. Allerg. (Budap.), 2, 72. CONTARDO, R. (1956). A.M.A. Arch. Ophthal., 56, 568.

DACIE, J. V. (1956). "Practical Haematology", 2nd ed. Churchill, London. HILL, L. C. (1957). Brit. med. J., 2, 655.

HogAN, M. J., Kimura, S. J., and ThyGeson, P. (1957). A.M.A. Arch. Ophthal., 57, 400.

LuDWIG, K. (1960-62). “A szombathelyi Markusovszky Kórház évkönyve”, p. 331.

(1963). Haemat. hung., 3, fasc. 1, p. 39.

Maumenee, A. E. (1956). A.M.A. Arch. Ophthal., 56, 557.

PetránYI, G. (1958). Magy. Belorv. Arch., 11, 57.

SOFFER, L. J., and BADER, R. (1952). J. Amer. med. Ass., 149, 1002.

SURY, (1952). (Cited by Hogan and others, 1957).

Ten Doesschate, J. (1956). Ophthalmologica (Basel), 132, 153.

ThOMAS, C. L. (1955). "The Cornea". Thomas, Springfield, Ill.

TumultY, P. A. (1954). J. Amer. med. Ass., 156, 947.

VACHTENHEIM, J., and SMID, V. (1962). Z. ges. inn. Med., 17, 327. 